\title{
Does Smearing Inoculum Reflect the Bacterial Composition of the Smear at the End of the Ripening of a French Soft, Red-Smear Cheese?
}

\author{
C. Feurer, ${ }^{1,2}$ T. Vallaeys, ${ }^{2,3}$ G. Corrieu, ${ }^{1}$ and F. Irlinger ${ }^{1}$ \\ ${ }^{1}$ Laboratoire de Génie et Microbiologie des Procédés Alimentaires and \\ ${ }^{2}$ Equipe Département Microbiologie, INRA, 78850 Thiverval-Grignon, France \\ ${ }^{3}$ Laboratoire de Génomique des Microorganismes Pathogènes, \\ Institut Pasteur, France
}

\begin{abstract}
The microbial community composition and dynamics during the production of a French soft, red-smear cheese were investigated. The colonization efficiency of the smearing inoculum was followed, and the parts played by the inoculum used and the resident microflora were tentatively estimated. Single-strand conformation polymorphism analysis (SSCP) was applied to 2 productions of a soft, red-smear cheese produced by the same dairy plant at 4-mo intervals. Microbial composition of the different cheese samples analyzed was found to be reproducible from one production to another. However, the composition of the surface flora of both cheeses at the end of the ripening did not reflect the composition of the smearing inoculum used, qualitatively as well as quantitatively. These results were confirmed by those obtained when assessing the microbial composition of the culturable flora by the spread plate technique. The inoculum used by the industry had low resiliency potentialities against colonization of cheeses by resident organisms. Therefore, fitness and colonization potential of smearing inocula should be carefully assessed by the industry before use. The use of Arthrobacter strains as part of the smearing inoculum should be evaluated.

(Key words: red-smear soft cheese, smearing inoculum, colonization potentiality, single-strand conformation polymorphism)
\end{abstract}

Abbreviation key: BHI = brain heart infusion, SSCP $=$ single-strand conformation polymorphism.

\section{INTRODUCTION}

Smear-ripened cheeses are mostly produced in France, Belgium, Germany, and Austria. These cheeses are characterized by the development of a mixed flora of yeasts and bacteria on their surfaces, which gives

Received January 27, 2004.

Accepted May 15, 2004.

Corresponding author: F. Irlinger; e-mail: irlinger@grignon. inra.fr. the typical red and glistening so-called "smear" appearance to the cheese (Reps, 1993).

Traditionally, their production has involved a common step of old-young smearing, i.e., the transfer of an undefined microflora washed off from the surface of ripened cheeses to young unripened cheeses. This process enables the transfer of desirable microorganisms for the ripening of young cheeses but could also transfer harmful organisms (Bockelmann and Hoppe-Seyler, 2001). Today, this former know-how is derogating to all good manufacturing practices. In modern industrial production, this step has been replaced by inoculation with controlled and standardized ripening cultures to meet sanitary requirements and to maintain reproducible organoleptic properties of the cheese along time. The choice and development of adapted starters and secondary adjunct cultures are essential. They have to be adjusted to the technological properties of the cheese, as an unbalanced cheese flora will allow undesirable contaminants to grow or inadequate organoleptic properties to develop. The composition of the smearing inocula was established according to the scientific knowledge of the diversity of the microbial flora present at the surface of red-smear cheeses. Reported findings suggested that, at the end of ripening, this microbial consortium was mainly composed of Gram-positive bacteria, including Micrococcus, Staphylococcus, and various coryneform species, such as Corynebacterium sp., Arthrobacter sp., and Brevibacterium linens (El-Erian, 1969; Lenoir, 1984; Seiler, 1986; Eliskases-Lechner and Ginzinger, 1995; Valdès-Stauber et al., 1997). However, it has been thought for some time that Brevibacterium linens was the main bacterium involved in the characteristic appearance and, thus, in the ripening of redsmear cheeses because of its orange pigmentation (Reps, 1993). For this reason, in industrial processes, smear cheeses are often intentionally inoculated with $B$. linens by washing or spraying the cheeses in a saline solution containing the microorganism. It is now widely reported that $B$. linens is not a dominant species of the ripening flora even if it is still used as the major component of ripening cultures (Eliskases-Lechner and 
Ginzinger, 1995; Brennan et al., 2002). In addition, recent results showed that the orange color was most likely due to the interactions between yellow-pigmented Arthrobacter sp. and other microorganisms, such as proteolytic bacteria in the surface flora (Bockelmann and Hoppe-Seyler, 2001; Bockelmann, 2002) or yeasts (Leclercq-Perlat et al., accepted).

The formation of the smear during ripening is an essential step, as bacteria of the smear determine some of the main organoleptic properties of the cheese, such as color, flavor, and texture (Reps, 1993). However, many factors can influence the composition and growth rate of the smear microflora, including environmental parameters (temperature and humidity in the ripening room), water activity of the rind, $\mathrm{pH}$ and salt content at the cheese surface, composition of the particular "home flora" of the dairy plant, and growth rate and microbial interactions on such cheeses during ripening (Reps, 1993). This last point is poorly documented and most probably very complex.

Various PCR-based molecular fingerprinting methods have been developed to assess bacterial community structure and evolution. These include denaturing gradient gel electrophoresis (Coppola et al., 2001; Randazzo et al., 2002), temperature gradient gel electrophoresis (Zoentendal et al., 2000), temporal temperature gel electrophoresis (Ogier et al., 2002), and singlestrand conformation polymorphism (SSCP) (Zumstein et al., 2000; Duthoit et al., 2003). The last method makes use of the fact that a single base modification can change the conformation of single-stranded DNA molecules, leading to different electrophoretic mobilities in a nondenaturing gel (Orita et al., 1989). Therefore, DNA fragments of the same size, but with a different base composition, can be separated (Hayashi, 1991). Globally, from a microbial community, the result obtained is a profile of peaks in which each peak corresponds to the sequence of one microorganism. However, elution of divergent sequences in a same peak, as well as visualization of different peaks corresponding to the nonredundant copies of $16 \mathrm{~S}$ rRNA loci of the same microorganism, can be observed. Despite these limitations, the electrophoretic properties of a peak remain reproducible and always correspond to the elution of the same component of the microflora. Therefore, this method was chosen in this study.

The aim of the present study was to follow the microbial community composition and dynamics during the production of a registered designation of origin soft redsmear cheese obtained from pasteurized milk to evaluate the colonization potentialities of the inoculum introduced. The SSCP analysis was applied to 2 productions of the same variety of soft red-smear cheese obtained from the same producer at a 4-mo interval. In parallel, the standard spread plate technique was also applied to all samples.

\section{MATERIALS AND METHODS}

\section{Cheese Samples}

The cheese sample analyzed in this study is a French, soft, red-smear cheese obtained from a dairy plant that produces registered designation of origin red-smear cheeses. This cheese is made from pasteurized cow milk using defined starters and secondary adjunct cultures. Cheeses are smeared several times with a brine containing secondary adjuncts during the course of the ripening process. Productions of January (Production J) and April (Production A) were analyzed. Analyses were conducted at different steps of the cheese-making process. Samples were collected from the pasteurized milk once inoculated with the starter culture (d 1), from the smearing culture used (d 3), and from cheese samples recovered at the end of the ripening period just before wrapping (d 21) and $10 \mathrm{~d}$ after wrapping (d 31). The cheese samples were immediately subjected to bacteriological analysis and stored at $-80^{\circ} \mathrm{C}$ for subsequent SSCP analysis. The culturable fraction of the bacterial flora was enumerated for all samples on brain heart infusion (BHI; Biokar Diagnostics, Beauvais, France) agar medium using the spread plate technique. A representative sample of each morphotype was then subcultured for subsequent DNA extraction and was identified by sequencing of its $16 \mathrm{~S}$ rRNA gene. Enumeration of the yeast flora was determined on yeast extract glucose chloramphenicol agar (Biokar Diagnostics). The yeasts were identified by comparing their SSCP profiles with a databank of reference strains of our laboratory (Laboratoire de Génie et Microbiologie des Procédés Alimentaires, unpublished data).

\section{Total Bacterial DNA Extraction from Isolated Morphotypes and Cheese Samples}

Cultures from isolated colonies were scraped from the agar plates and resuspended in $200 \mu \mathrm{L}$ of TE buffer (10 $\mathrm{m} M$ Tris/HCL and $1 \mathrm{~m} M$ EDTA; pH 7.4). Each suspension was transferred to a 2-mL tube (Sarstedt, Nümbrecht, Germany) containing $20 \mu \mathrm{L}$ of $10 \%$ sodium dodecyl sulfate, $0.2 \mathrm{~g}$ of acid-washed glass beads (212 to $300 \mu \mathrm{m}$; Sigma-Aldrich, St. Louis, MO), and 1 vol of phenol-chloroform-isoamyl alcohol 25:24:1 ( $\mathrm{vol} / \mathrm{vol}$ ). Tubes were shaken twice for $40 \mathrm{~s}$ in the Savant FastPrep instrument (Savant, Farmingdale, NY) and then centrifuged at 14,000 rpm for $20 \mathrm{~min}$. The upper phase containing DNA was precipitated with absolute ethanol at $-20^{\circ} \mathrm{C}$. After centrifugation, pellets were washed 
with $70 \%$ ethanol, dried, and dissolved in $200 \mu \mathrm{L}$ of TE buffer.

For DNA extraction of cheese samples (pasteurized milk, smearing culture, rind of the cheese at $d 21$ and 31), $1 \mathrm{~g}$ of each sample was homogenized in $400 \mu \mathrm{L}$ of TE buffer containing $25 \mu \mathrm{L}$ of $10 \% \mathrm{~N}$-lauroylsarcosine. Suspensions were treated with $50 \mu \mathrm{L}$ of Proteinase $\mathrm{K}$ $\left(40 \mathrm{mg} / \mathrm{mL}\right.$ ) for $2 \mathrm{~h}$ at $55^{\circ} \mathrm{C}$. Samples were then treated as described previously. The DNA extracted from cheese samples were purified using the Qiaquick PCR purification kit (Qiagen, Hilden, Germany) prior to amplification of the 16S rRNA gene.

\section{S rRNA Gene Amplification}

The 16S rRNA genes from both cheese samples and isolated colonies were amplified by PCR using the universal primers A 5'-AGAGTTTGATCCTGGCTCAG-3', position 8 to 27 (Escherichia coli numbering [Brosius et al., 1978]) and H 5'-AAGGAGGTGATCCAGCCGCA$3^{\prime}$, position 1541 to 1522 (Böttger, 1989). Each reaction was performed in a $100-\mu \mathrm{L}$ volume containing $20 \mathrm{pM}$ of each primer, $2.5 \mathrm{U}$ of Thermus aquaticus DNA polymerase (Qbiogene, Montréal, Quebec), $10 \mu \mathrm{L}$ of the corresponding reaction buffer containing $2.5 \mathrm{mM} \mathrm{MgCl}$, $0.3 \mathrm{~m} M$ of each dNTP (PE Applied Biosystems, Foster City, CA), and $1 \mu \mathrm{L}$ of template DNA. Polymerase chain reaction amplification was carried out in a GeneAmp thermal cycler (Perkin-Elmer, Wellesley, MA) using the following thermal cycles: $94^{\circ} \mathrm{C}$ for $4 \mathrm{~min}$, followed by 25 cycles at $94^{\circ} \mathrm{C}$ for $1 \mathrm{~min}, 57^{\circ} \mathrm{C}$ for $1 \mathrm{~min}, 72^{\circ} \mathrm{C}$ for 2 min, with a final extension step at $72^{\circ} \mathrm{C}$ for $5 \mathrm{~min}$. The PCR products were electrophoresed in a $1 \%$ (wt/vol) agarose gel and visualized by ethidium bromide staining.

\section{Cloning and Sequencing of 16S rRNA Gene Amplified from Cheese Samples}

The PCR products amplified from total DNA extracted from cheese samples were ligated into the pCR4-TOPO vector (Invitrogen, Carlsbad, CA). Recombinant pCR4-TOPO plasmids were used to transform E. coli TOP10 One Shot competent cells as specified by the manufacturer (Invitrogen). For each cheese DNA sample, 100 transformant clones were randomly picked for plasmid extraction (Birnboim and Doly, 1979). Inserts were amplified by PCR using universal external primers $\mathrm{A}$ and $\mathrm{H}$ and sequenced using the same primers and the T. aquaticus DyeDeoxy terminator cycle sequencing kit, according to the manufacturer's instructions (PE Applied Biosystems).

\section{$16 S$ rRNA Gene Sequencing of Isolated Morphotypes}

The PCR products from selected colonies were treated with Exonuclease I (3 U) (USB, Cleveland, Ohio) and Shrimp Alkaline Phosphatase (1 U) (USB) for $15 \mathrm{~min}$ at $37^{\circ} \mathrm{C}$ followed by a 15 -min denaturation step at $80^{\circ} \mathrm{C}$. The PCR products were then sequenced using the $T$. aquaticus DyeDeoxy terminator cycle sequencing kit according to the manufacturer's instructions. Amplicons were sequenced directly using the external primers $\mathrm{A}$ and $\mathrm{H}$ listed previously and 6 internal sequencing primers: 5'-CTCCTACGGGAGGCAGCAGT-3', position 339 to 358 ( $E$. coli numbering system); 5'-ACTGCTGC CTCCCGTAGGAG-3', position 358 to 339 ; $5^{\prime}$-CGTGC CAGCAGCCGCGGTAAT-3', position 514 to 534; 5'-C ATGTGGTTTAATTCGA-3', position 947 to $964 ; 5^{\prime}$-T CGAATTAAACCACATGC-3', position 964 to 947 ; and 5'-AGGGTTGCGCTCGTTGCGG-3', position 1115 to 1097.

Unincorporated dye terminators were removed by precipitation of the termination products with 76\% (vol/ vol) ethanol for $30 \mathrm{~min}$, washed with $70 \%$ ethanol, and resuspended in $10 \mu \mathrm{L}$ of $0.3 \mathrm{~m} M$ EDTA buffer.

\section{Computational Data and Sequence Analysis}

Electrophoresis, data collection, and analysis were performed using an ABI PRISM 3700 Genetic Analyzer (PE Applied Biosystems). Sequences were assembled from the corresponding chromatograms using PHRED (Phragment editing) (Ewing and Green, 1998a, 1998b) and PHRAP (Phragment assembly program) (P. Green, unpublished, 1994), and edited using CONSED (consensus sequence editing) to resolve any ambiguities (Gordon et al., 1998). The resulting 16S rRNA sequences were compared with DNA sequences of the GenBank/EMBL/DDBJ/PDB databases using the Blast program (Altschul et al., 1997). The $97 \%$ sequence similarity limit required to consider 2 strains as belonging to the same species was used (Stackebrandt and Goebel, 1994).

\section{SSCP-PCR Amplification}

For assessment of the bacterial community, the target DNA amplified was the variable region V3 of the 16S rRNA gene. Primers used were w49 and NED labelled w34 (PE Applied Biosystems) as described previously (Duthoit et al., 2003). Each reaction was performed in a $50-\mu \mathrm{L}$ volume containing $100 \mathrm{ng} / \mathrm{mL}$ of each primer, 2.5 U of Pyrococcus furiosis turbo DNA polymerase (Stratagene, La Jolla, CA), $5 \mu \mathrm{L}$ of the corresponding reaction buffer containing $2.5 \mathrm{mM} \mathrm{MgCl} 2,0.3 \mathrm{mM}$ of each dNTP (PE Applied Biosystems), and $1 \mu \mathrm{L}$ of 
Table 1. Results of the enumeration of the microbial flora including bacteria and yeasts in both productions by the spread plate technique. Concentrations are expressed in cfu/g.

\begin{tabular}{|c|c|c|c|c|c|c|c|c|}
\hline Organism & \multicolumn{4}{|c|}{ January production } & \multicolumn{4}{|c|}{ April production } \\
\hline Brevibacterium linens & - & $2.1 \times 10^{8}$ & $3.0 \times 10^{7}$ & $3.0 \times 10^{6}$ & - & $3.4 \times 10^{8}$ & $2.8 \times 10^{6}$ & - \\
\hline Arthrobacter sp. & - & - & $1.0 \times 10^{8}$ & $4.5 \times 10^{9}$ & - & - & - & - \\
\hline Arthrobacter arilaitensis & - & - & $1.5 \times 10^{8}$ & $1.5 \times 10^{10}$ & - & - & $3.6 \times 10^{7}$ & $1.4 \times 10^{8}$ \\
\hline Staphylococcus xylosus & - & - & - & - & - & - & - & - \\
\hline
\end{tabular}

${ }^{\mathrm{a}} \mathrm{nd}=$ Not determined.

template DNA. Polymerase chain reaction amplification was carried out in a GeneAmp thermal cycler (Perkin-Elmer, Wellesley, MA) using the following thermal cycles: $94^{\circ} \mathrm{C}$ for $2 \mathrm{~min}$, followed by 25 cycles at $94^{\circ} \mathrm{C}$ for $30 \mathrm{~s}, 61^{\circ} \mathrm{C}$ for $30 \mathrm{~s}, 72^{\circ} \mathrm{C}$ for $30 \mathrm{~s}$, with a final extension step at $72^{\circ} \mathrm{C}$ for $10 \mathrm{~min}$. For assessment of the yeast community, the primer pair NL3-NL4 was used to amplify the 5' end of 28S rDNA (Voigt et al., 1999). Primer NL4 was labeled with hexachloro derivative of fluorescein. The PCR reactions were prepared as previously detailed except that primer concentration was $0.01 \mu \mathrm{g} /$ $\mathrm{mL}$. The PCR temperature profile included an initial denaturation step of $4 \mathrm{~min}$ at $94^{\circ} \mathrm{C} ; 30$ cycles of $30 \mathrm{~s}$ at $94^{\circ} \mathrm{C}$ for DNA denaturation, $30 \mathrm{~s}$ at $57^{\circ} \mathrm{C}$ for primer extension, $1 \mathrm{~min} 30 \mathrm{~s}$ at $72^{\circ} \mathrm{C}$, and a final extension step of 5 min at $72^{\circ} \mathrm{C}$.

The PCR products were electrophoresed in a $0.8 \%$ (wt/vol) agarose gel in $1 \times$ TBE ( $89 \mathrm{~m} M$ Tris base, 89 $\mathrm{m} M$ borate, $2 \mathrm{~m} M$ EDTA). The DNA bands were visualized by ethidium bromide staining. The PCR products were purified using the Qiaquick PCR purification kit (Qiagen). Prior to SSCP analysis, PCR products were diluted 10- to 30 -fold, depending on the band intensity on the $0.8 \%$ agarose gel.

\section{SSCP Analysis}

The SSCP analysis was performed as previously described (Duthoit et al., 2003) except that electrophoresis conditions were different. To obtain an optimal resolution of the peaks, injection and electrophoresis voltages of $10 \mathrm{~V}$ and $13 \mathrm{kV}$ were used, respectively. The SSCP patterns were analyzed using the GeneScan Analysis software (Applied Biosystems). To assign peaks on all cheeses, bacterial SSCP patterns, the V3 region of the 16S rRNA of 100 clones were additionally amplified and subjected to an SSCP analysis. The individual and cumulated SSCP peak fingerprints obtained were then compared with those of the cheeses sampled.

\section{Screening for Surface-Smear Microorganisms Inhibitory to Brevibacterium linens}

Screening analysis was performed according to the procedure of Carminati et al. (1999) modified as described subsequently. Strains isolated from the surface of all samples investigated (see Table 1) were grown in $\mathrm{BHI}$ broth at $25^{\circ} \mathrm{C}$ for $48 \mathrm{~h}$. The cultures were then assayed for their inhibitory activity as follows: $20 \mu \mathrm{L}$ of culture were spotted on the surface of polycarbonate membrane filters (pore size $=0.2 \mu \mathrm{m}$; Millipore, Billerica, MA) placed on BHI agar plates ( $\mathrm{pH}$ 6.8) and incubated for $48 \mathrm{~h}$ at $25^{\circ} \mathrm{C}$. Filters were removed, and 100 $\mu \mathrm{L}$ of the culture of the indicator strain $B$. linens were spread at the surface of the agar. The $B$. linens culture was prepared in $\mathrm{BHI}$ broth at $25^{\circ} \mathrm{C}$ for $48 \mathrm{~h}$. After further incubation at $25^{\circ} \mathrm{C}$ for $48 \mathrm{~h}$, the presence of inhibition zones was evaluated. The positive control of diffusion of inhibitory substances was determined by culturing a strain of Listeria monocytogenes and B. linens OC2, which has been found to produce a bacteriocinlike substance with an antagonistic effect against the former (Maisnier-Patin and Richard, 1995).

\section{RESULTS}

\section{SSCP Profiles Analysis}

In this work, we followed 2 productions of a French, soft, red-smear cheese by a qualitative analysis of the diversity and composition of the microbial community. For each production, SSCP profiles of the milk after pasteurization, the smearing inoculum, and cheese samples just before wrapping and $10 \mathrm{~d}$ after wrapping were generated.

The SSCP profiles of the yeast community of both productions obtained after amplification of the $5^{\prime}$ end of the $28 \mathrm{~S} \mathrm{rDNA}$ gene isolated from the smearing inoculum and cheese samples are shown in Figure 1. In both productions, SSCP patterns of the smearing inoculum 
$\begin{array}{lllllllllllllllll}7050 & 7080 & 7110 & 7140 & 7170 & 7200 & 7230 & 7260 & 7290 & 7320 & 7350 & 7380 & 7410 & 7440 & 7470 & 7500\end{array}$
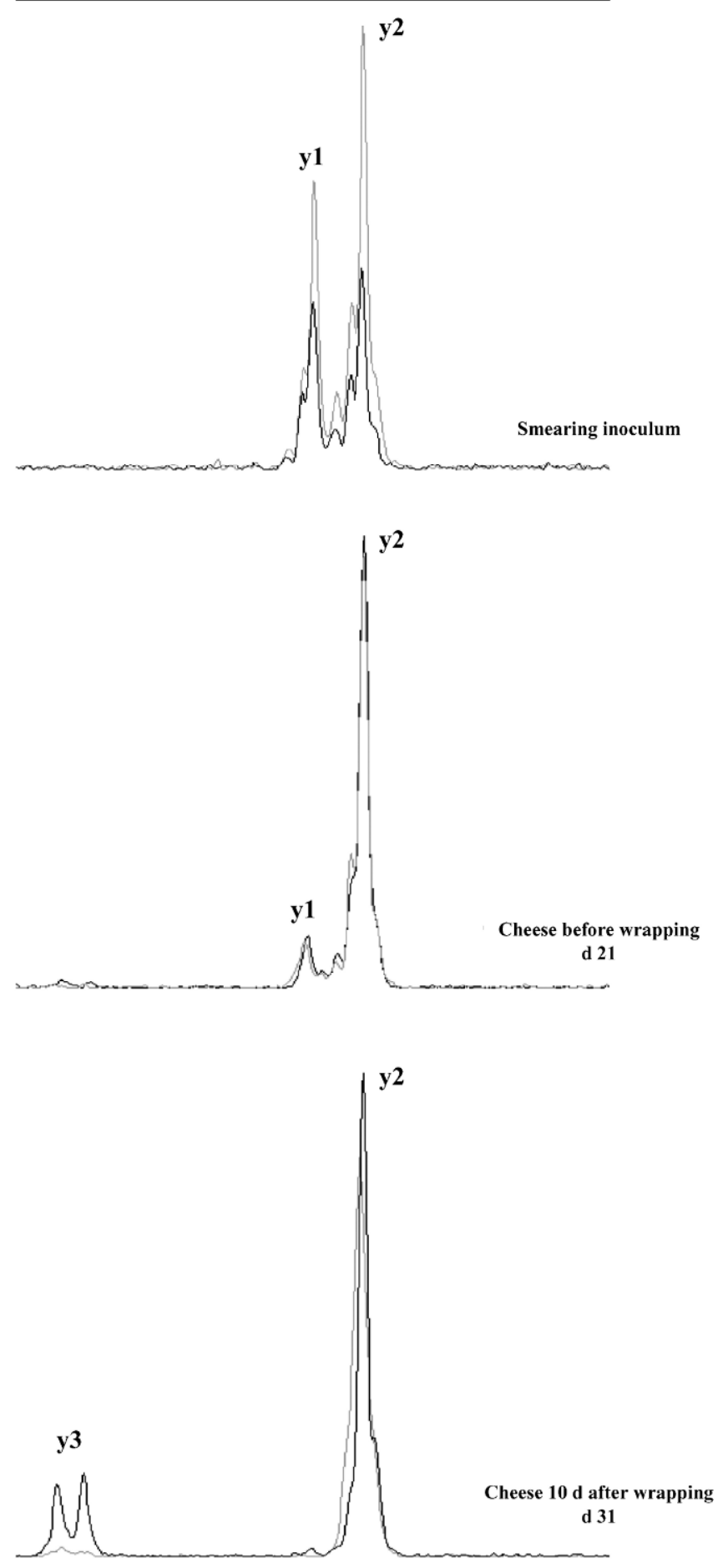

Figure 1. Single-strand conformation polymorphism patterns of PCR-amplified $5^{\prime}$ end of $28 \mathrm{~S}$ rDNA gene fragments from the yeast community of 2 productions of a French, soft, red-smear cheese at different times of the cheese-making process. Production A (April; heavy black line) was made 4 mo later than Production J (January; grey line). X-axis: elution in scans (unit of GeneScan software). The positions and labelling of peaks discussed in the text are indicated. Peak y1 = Rhodoturula mucilaginosa; peak y2 = Debaryomyces hansenii, and Peak y3 = Geotrichum candidum. showed the presence of 2 peaks corresponding to 2 distinct yeast strains. Peak y1 corresponded to the sequence of Rhodotorula mucilaginosa, whereas Peak y2 corresponded to the sequence of a strain of Debaryomyces hansenii. According to the relative intensity of the peaks, both species were inoculated at the same concentrations. The SSCP profiles of the cheese just before wrapping ( $\mathrm{d} 21$ ) showed that both $R$. mucilaginosa and $D$. hansenii were still present at that time, but while Peak y2 was largely dominant, Peak y1 tended to disappear in both productions. The intensity of Peak y1 was already dropping after $2 \mathrm{~d}$ of ripening (data not shown). Ten days after wrapping, the SSCP profiles showed that Peak y2, corresponding to a sequence of $D$. hansenii, remained still largely dominant, and Peak y1 was not detected. However, we noted the appearance in both productions of a subdominant Peak y3 that corresponded to the elution of a sequence of Geotrichum candidum that was not inoculated. Globally, the yeast composition and dynamics of the SSCP profiles between productions remained similar, but the relative concentrations of the 3 species varied.

The SSCP profiles of the bacterial community of both productions obtained after amplification of the V3 region of $16 \mathrm{~S}$ rRNA isolated from milk, smearing inoculum, and cheese samples are shown in Figure 2. The SSCP patterns of the milk (d l) allowed us to characterize 4 distinct peaks corresponding to the lactic acid bacteria of the starter culture (Peak l on the milk SSCP profile) in both productions.

In Productions $J$ and A, SSCP patterns of the smearing inoculum presented 2 peaks, one of which (Peak l) was already identified in the milk, whereas the other (Peak b) corresponded to the sequence of a strain of $B$. linens. According to the relative intensity of the peaks, the concentration of $B$. linens was 4 times that of the lactic acid bacterium in the smearing inoculum, and thus appeared dominant in the inoculum.

The SSCP fingerprints of the cheese just before wrapping showed that Peak 1 largely dominated the SSCP profile of the smear flora. We also noted the presence of a peak corresponding to the sequence of a strain of Staphylococcus xylosus (Peak s) in both productions. Other peaks that eluted between 5900 and 6040 scans corresponded to sequences of gram-negative bacteria (Peak g). Peak b corresponding to the elution of a sequence of $B$. linens was not detected in the profiles. This did not mean that the corresponding sequences were not present in the sample, but they were subdominant and, therefore, not detected by SSCP analysis. However, we noted the appearance of a subdominant Peak a that corresponded to the sequence of Arthrobacter sp. Ten days after wrapping, the SSCP patterns showed that Peak a, corresponding to the sequence of 

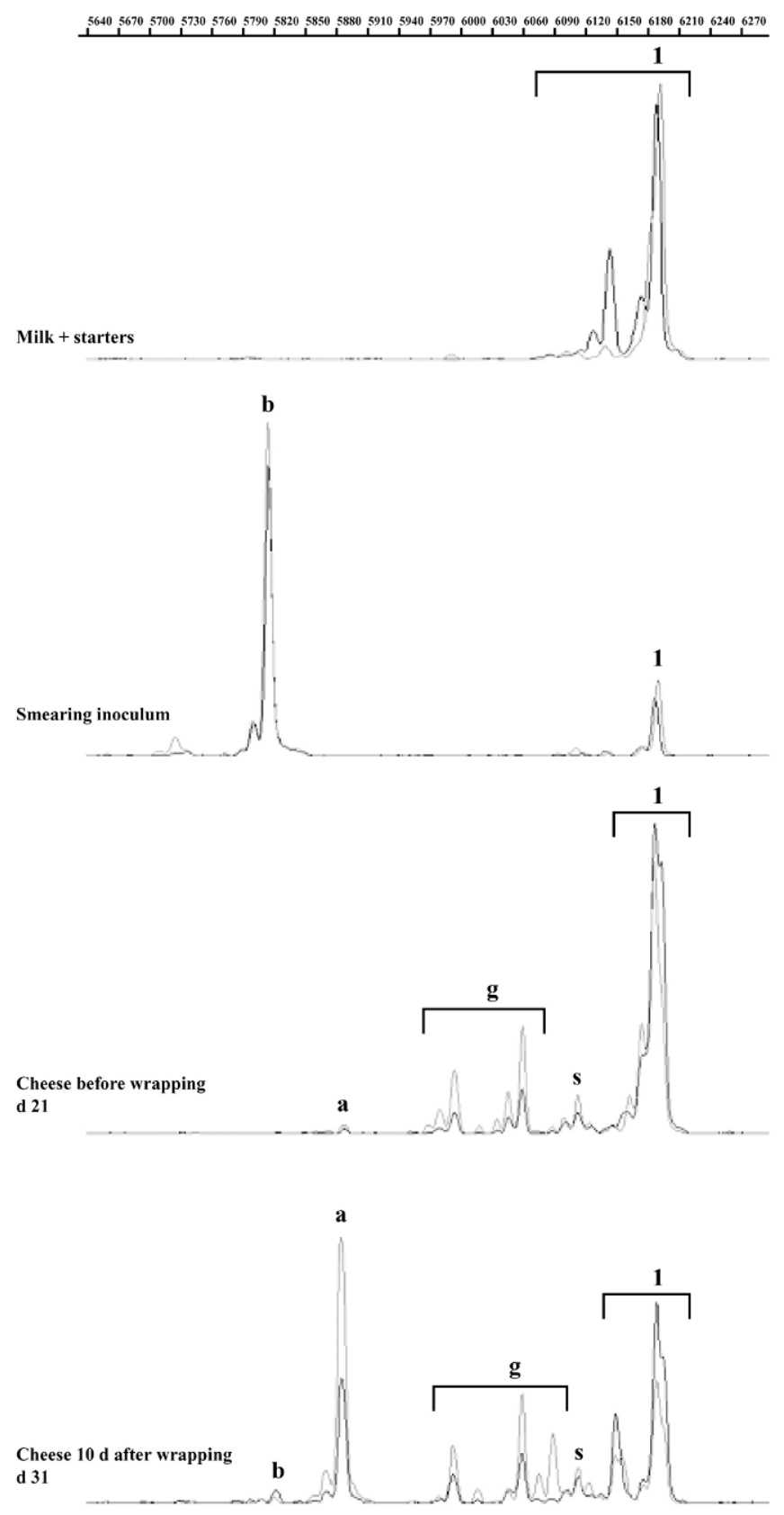

Figure 2. Region V3 single-strand conformation polymorphism patterns of PCR-amplified 16S rDNA gene fragments from the bacterial community of 2 productions of a French, soft, red-smear cheese at different times of the cheese-making process. Production A (April; heavy black line) was made 4 mo later than Production J (January; grey line). X-axis: elution in scans (unit of GeneScan software). The positions and labelling of peaks discussed in the text are indicated. Peak $\mathrm{l}=$ lactic acid bacteria, Peak $\mathrm{b}=$ Brevibacterium linens, Peak $\mathrm{a}=$ Arthrobacter arilaitensis and Arthrobacter sp., Peak g = Gramnegative bacteria, and Peak $\mathrm{s}=$ Staphylococcus xylosus

Arthrobacter sp., was largely dominating the profile of the Production A. However, Peak a was equally dominant with Peak l (lactic acid bacteria) in Production J.
In both productions, we noted the presence of $B$. linens as a minor peak.

When comparing the SSCP profiles between Productions $\mathrm{J}$ and $\mathrm{A}$, bacterial composition and dynamics of the SSCP patterns were almost identical. However, the relative concentration of some members of the smear flora varied from one production to another. Globally, throughout both production processes, it appeared that Peak l, corresponding to the sequences of lactic acid bacteria, was high and remained predominant until the end of the ripening. On the contrary, Peak b, corresponding to the sequence of $B$. linens, which was highly dominant in the profiles of the smearing inoculum, could not be detected in the profiles of the cheese at $d$ 21 . However, it was detected in the profiles of the cheese at $\mathrm{d} 31$ as a minor peak. At that time, Peak a, corresponding to the sequence of Arthrobacter sp., which appeared at $d 21$, prevailed over all other peaks of the profiles. However, this species was not part of the smearing inoculum.

\section{The Culturable Fraction of the Cheese Samples}

Results obtained when enumerating the culturable microbial fraction of the different samples are shown in Table 1. Globally, bacterial composition of the various samples was similar from one production to another. The concentration of $B$. linens, which was $2.1 \times 10^{8}$ and $3.4 \times 10^{8} \mathrm{cfu} / \mathrm{g}$ in the smearing inoculum in Productions $\mathrm{J}$ and A, respectively, fell to $3.0 \times 10^{6} \mathrm{cfu} / \mathrm{g}$ at $10 \mathrm{~d}$ after wrapping in Production $J$ and was not detected further in Production A. Arthrobacter sp. was not detected before d 21 (data not shown) and represented, at that time, a percentage $<1 \%$ of the total bacterial flora in both productions. Ten days after wrapping, it represented around 60 and $51 \%$ of the total bacterial flora in Productions $\mathrm{J}$ and A, respectively. Thus, results of the SSCP analysis of the bacterial fraction were confirmed for both productions by results of the spread plate technique. Differential counting of the yeast fraction could not be performed.

\section{Heterogeneity of Arthrobacter Strains Identified}

Colonies of Arthrobacter sp. strains that were dominant on the cheese surface at $d 31$ were morphologically heterogeneous on brain heart agar plates from one production to another as well as within a production (Table 1). To ensure that the different colonies did correspond to distinct species, we tried to identify those strains at the species level by data mining of the resulting $16 \mathrm{~S}$ rRNA sequences in the GenBank/EMBL/DDBJ/PDB databases. Sequences of Arthrobacter isolated in the production made in April were unique and corres- 
ponded to a newly described species of Arthrobacter arilaitensis (Irlinger et al., unpublished data, 2004). In the January production, 2 different sequences of Arthrobacter were identified: one corresponded to the sequence of Arthrobacter arilaitensis; the sequence of the other strain showed only $96 \%$ similarity with that of Arthrobacter arilaitensis, its nearest phylogenetic neighbor and, thus, could correspond to a new undescribed Arthrobacter species.

\section{Growth Reduction of Brevibacterium linens}

We tried to discern why $B$. linens became subdominant, as cheeses have been smeared massively several times with this organism during ripening. Thus, we evaluated the putative production of substances inhibitory to $B$. linens by the culturable surface-smear microorganisms. However, none of the cheese-smear isolates showed any inhibition activity when tested against $B$. linens.

The $\mathrm{pH}$ and salt content at the surface of the cheeses were measured at the end of the ripening (d 21) and were 6.0 and $1.7 \%$, respectively, in both productions. Growth measurements of $B$. linens at various $\mathrm{pH}$ values (6.0, 6.5, and 6.8) and various temperatures (14 ${ }^{\circ}$ and $25^{\circ} \mathrm{C}$ ) were performed and compared with those of both species of Arthrobacter isolated. For all tested conditions, growth of $B$. linens was always slower compared with both Arthrobacter species (data not shown).

\section{DISCUSSION}

We evaluated the microbial community composition and dynamics of 2 pasteurized French, red-smear, soft cheeses obtained from pasteurized milk and produced at a 4-mo interval to determine the impact of the smearing inoculum on the composition of the smear at the end of the ripening. In both productions, we demonstrated that $B$. linens, which was intentionally and massively inoculated, almost disappeared from their surface after $21 \mathrm{~d}$ of ripening. Ten days after wrapping, the results showed that the bacterial flora was dominated by a species of Arthrobacter. Thus, we demonstrated that the species composition of the inoculum does not systematically govern the evolution of the microbial diversity of the cheese-ripening flora. Indeed, both bacteriological counts and SSCP patterns of the smearing inoculum differed widely from their counterparts in the cheese at the end of ripening.

Globally, the reproducibility of the results obtained between the methods used, as well as between productions, demonstrated the temporal stability of the smear flora evolution of the cheeses within this particular dairy plant.
Potentialities and limitations of the SSCP technique in the analysis of bacterial communities have been discussed recently (Zumstein et al., 2000; Duthoit et al., 2003). In this study, SSCP analysis was performed on DNA and, thus, did not give a picture of the metabolically active populations. However, the SSCP technique gave a general overview of the relative abundance of the dominant members of the surface flora and their evolution during cheese production. As SSCP is not a quantitative method, proportions of the populations could be estimated rather than expressed as absolute values. Subdominant members could not be assessed using this technique because they were not differentiated from background noise. Both quantitative and qualitative variations in species composition could be observed according to the method used, and both approaches carried their own bias. Whereas results of culture-dependent techniques were strongly linked to the culture medium used, DNA-based approaches were prone to other bias (dead cells, preferential lysis and amplification, level of dilution of the PCR product, chimeras, etc.) (Farrelly et al., 1995; Wintzingerode et al., 1997). Indeed, in some cases, some strains were not systematically detected using the spread plate technique, such as given gram-negative bacteria. Conversely, strains detected using a culturable approach were not detected using SSCP. This was particularly the case for $B$. linens at low concentrations, for which results between the cultivable approach and SSCP did not systematically correlate. Therefore, both methods were informative and complementary in the study of the cheese samples, and the need to combine them is clearly illustrated here.

Several hypotheses could be formulated to explain the growth reduction of $B$. linens. First, the production of inhibitory substances by the smear flora, as reported by Brennan et al. (2002) in Gubbeen cheese, could be responsible for the drop in $B$. linens population. This hypothesis has been tested here according to standard methods. However, none of the cultured smear microorganisms produced any inhibitory substances. Alternatively, B. linens behavior could also be explained by the lack of available substrates, such as specific amino acids and vitamins usually produced by yeasts (Purko et al., 1951; Fleet, 1990), or inappropriate growth conditions (especially $\mathrm{pH}$, salt concentration, and temperature) (Reps, 1993). Indeed, growth of $B$. linens occurs when the $\mathrm{pH}$ of the cheese surface rises to $>5.8$ because of the uptake of lactic acid by yeasts (Kelly and Marquardt, 1939). In this study, the $\mathrm{pH}$ on the cheese surface at the end of the ripening was 6.0, which was too low for an optimal growth (i.e., an optimal metabolic activity of $B$. linens). The low increase in $\mathrm{pH}$ during ripening can be explained via chemical reasons (i.e., too 
high buffer capacity of the curd), physical reasons (i.e., a diffusion problem of lactic acid in the curd), or biological reasons (i.e., a problem of deacidification by the yeast community). Indeed, the strain of $D$. hansenii used in the inoculum may not be efficient enough for deacidifying the curd. It has also been reported that the growth rate of $B$. linens was lower than that of other surface bacteria under cheese-ripening conditions at $\leq 21^{\circ} \mathrm{C}$ (Bockelmann, 2002), which is the case in this production. Finally, the drop in $B$. linens population could be explained by a competitive interaction with the members of the smear microflora (Reps, 1993). It is most likely that adventitious gram-negative bacteria and Arthrobacter species grew faster than $B$. linens in this specific technological environment. Alternatively, negative interactions existing between yeasts and bacteria or between bacteria can occur. However, low concentration of $B$. linens in cheese is probably beneficial, as large concentrations would produce an intense ammoniac smell, which would not be appreciated by consumers (Bockelmann, 2002).

We demonstrated that $10 \mathrm{~d}$ after wrapping, the spreading of strains of the Arthrobacter species largely prevailed over the growth of $B$. linens. This result was not surprising considering that they grew much faster than $B$. linens on agar plates. However, SSCP analysis and enumeration of the culturable flora could not detect their occurrence before d 21 (data not shown). Because Arthrobacter strains were not inoculated, it is probable that their growth took longer to reach detectable concentrations as compared with deliberately added cultures. However, Arthrobacter species are obligate aerobe microorganisms, thus their prevalence after wrapping under microaerophilic conditions is surprising. It can be speculated that high carbon dioxide concentrations were more favorable to the growth of Arthrobacter compared with that of the other microorganisms of the surface flora (Blickstad and Molin, 1983). Such hypothesis has to be tested. The origin of Arthrobacter sp. in this cheese is not clear, but walls of the ripening room, shells, or hands of cheese makers are possible sources. Species of Arthrobacter are ubiquitous in the environment. They have been isolated in soil (Conn, 1928; Axelrood et al., 2002) and were also associated with biofilms on wall paintings (Heyrman et al., 1999; SchabereiterGurtner et al., 2001). It would, therefore, not be surprising that strains of Arthrobacter that we isolated were capable of forming biofilms at the surface of the walls of the dairy plant, thus colonizing the cheese productions. At least 2 strains of Arthrobacter were isolated, one of which, Arthrobacter arilaitensis, could be recovered from both productions. Arthrobacter arilaitensis constituted what could be called a resident adventitious "contaminant" in this particular dairy plant. It is fortu- nate and beneficial that Arthrobacter species colonized the cheese surface, as they are normal components of the surface flora of red-smear cheeses (Lenoir, 1984; Eliskases-Lechner and Ginzinger, 1995; ValdèsStauber et al., 1997; Brennan et al., 2002). On the SSCP profile, Peak a corresponded to the co-elution of both species of Arthrobacter recovered. The SSCP analysis did not distinguish them because the $\mathrm{V} 3$ region of their respective 16S rRNA gene was identical. To differentiate them, SSCP analysis of another region of this gene that is variable between these species has to be conducted. In this study, only a macroscopic observation of the bacterial colonies allowed their differentiation.

Similarly, gram-negative bacteria were also isolated in both productions, as previously reported by Bockelmann (2002), Maoz et al. (2003), and Feurer et al. (accepted). They certainly benefited from the nonimplantation of secondary adjunct cultures, such as B. linens. Globally, the same gram-negative species were recovered from one production to another. Thus, as in the case of Arthrobacter species, they represented adventitious resident "contaminants" of this dairy plant. The role of this resident adventitious flora is unknown. However, it seems not to affect the organoleptic properties of the cheeses.

Therefore, although $B$. linens was dominant in the smearing inoculum, the principal source of the cheese surface flora remained the cheese-making environment. In the case of this particular dairy plant, deliberate smearing with Arthrobacter strains isolated would be of interest for quick colonization of the cheese surface. Furthermore, it would be advisable to replace the yeast y1 used in the inoculum by another strain with better colonizing capacities. In a general manner, the assessment of fitness of all members of the smearing inoculum under the biological and technological parameters of the environment should be checked to know whether they do or do not permit a quick colonization of cheese surfaces before use by the industrials. This may help to prevent the development of undesirable flora, especially pathogens, and useless inocula costs. The present study shows that methods are now available for such controls.

\section{ACKNOWLEDGMENTS}

We thank Eric Spinnler for critical reading of the manuscript.

\section{REFERENCES}

Altschul, S. F., T. L. Madden, A. A. Schäffer, J. Zhang, Z. Zhang, W. Miller, and D. J. Lipman. 1997. Gapped BLAST and PSI-BLAST: A new generation of protein database search programs. Nucl. Acids Res. 25:3389-3402. 
Axelrood, P. E., M. L. Chow, C. S. Arnold, K. Lu, J. M. McDermott, and J. Davies. 2002. Cultivation-dependent characterization of bacterial diversity from British Columbia forest soils subjected to disturbance. Can. J. Microbiol. 48:643-654.

Birnboim, H. C., and J. Doly. 1979. A rapid alkaline extraction procedure for screening recombinant plasmid DNA. Nucl. Acids Res. 7:1513-1523.

Blickstad, E., and G. Molin. 1983. The microbial flora of smoked pork loin and frankfurter sausage stored in different gas atmospheres at $4^{\circ}$ C. J. Appl. Bacteriol. 54:45-56.

Bockelmann, W., and T. Hoppe-Seyler. 2001. The surface flora of bacterial smear-ripened cheeses from cow's and goat's milk. Int. Dairy J. 11:307-314.

Bockelmann, W. 2002. Development of defined surface starter cultures for the ripening of smear cheeses. Int. Dairy J. 12:123-131.

Böttger, E. C. 1989. Rapid determination of bacterial ribosomal RNA sequences by direct sequencing of enzymatically amplified DNA. FEMS Microbiol. Lett. 65:171-176.

Brennan, N., A. C. Ward, T. Bersford, P. Fox, M. Goodfellow, and T. Cogan. 2002. Biodiversity of the bacterial flora on the surface of a smear cheese. Appl. Environ. Microbiol. 68:820-830.

Brosius, J., M. L. Palmer, P. J. Kennedy, and H. F. Noller. 1978. Complete nucleotide sequence of 16S ribosomal RNA gene from Escherichia coli. Proc. Natl. Acad. Sci. USA 75:4801-4805.

Carminati, D., E. Neviani, G. Ottogalli, and G. Giraffa. 1999. Use of surface-smear bacteria for inhibition of Listeria monocytogenes on the rind of smear cheese. Food Microbiol. 16:29-36.

Conn, H. J. 1928. A type of bacteria abundant in productive soils, but apparently lacking in certain soils of low productivity. NY State Agric. Exp. Stn. Tech. Bull. 138:3-26.

Coppola, S., G. Blaiotta, D. Ercolini, and G. Moschetti. 2001. Molecular evaluation of microbial diversity occurring in different types of Mozzarella cheese. J. Appl. Microbiol. 90:414-420.

Duthoit, F., J. J. Godon, and M. C. Montel. 2003. Bacterial community dynamics during production of registered designation of origin Salers cheese as evaluated by 16S rRNA gene single-strand conformation polymorphism analysis. Appl. Environ. Microbiol. 69:3840-3848.

El-Erian, A.F.M. 1969. Bacteriological Studies on Limburger Cheese. Mededelingen van de Land-bouwhogeschool, Wageningen, The Netherlands.

Eliskases-Lechner, F., and W. Ginzinger. 1995. The bacterial flora of surface ripened cheese with special regard to coryneforms. Lait 75:571-584.

Ewing, B., and P. Green. 1998a. Base-calling of automated sequencer traces using PHRED. I. Accuracy assessment. Genome. Res. $8: 175-185$

Ewing, B., and P. Green. 1998b. Base-calling of automated sequencer traces using PHRED. II. Error probabilities. Genome Res. 8:186-94.

Farrelly, V., F. A. Rainey, and E. Stackebrandt. 1995. Effect of genome size and rrn gene copy number on PCR amplification of 16S rRNA genes from a mixture of bacterial species. Appl. Environ. Microbiol. 61:2798-2801.

Feurer, C., F. Irlinger, H. E. Spinnler, P. Glaser, and T. Vallaeys. 2004. Assessment of the rind microbial diversity in a farmhouseproduced versus a pasteurized industrially produced soft redsmear cheese using both cultivation and rDNA based methods. J. Appl. Microbiol. (accepted).

Fleet, G. H. 1990. Yeasts in dairy products. J. Appl. Bacteriol. 68:199-211

Gordon, D., C. Abajian, and P. Green. 1998. Consed: A graphical tool for sequence finishing. Genome Res. 8:195-202.

Hayashi, K. 1991. PCR-SSCP: A simple and sensitive method for detection of mutations in the genomic DNA. PCR Methods Appl. $1: 34-38$.
Heyrman, J., J. Mergaert, R. Denys, and J. Swings. 1999. The use of fatty acid methyl ester analysis (FAME) for the identification of heterotrophic bacteria present on three mural paintings showing severe damage by microorganisms. FEMS Microbiol. Lett. 181:55-62.

Kelly, C. D., and J. C. Marquardt. 1939. The influence of hydrogen ion concentration and salt on the surface flora of Limburger cheese. J. Dairy Sci. 22:309-320.

Leclercq-Perlat, M.-N., G. Corrieu, and H.-E. Spinnler. 2004. The color of Brevibacterium linens depends on the yeast used for cheese deacidification. J. Dairy Sci. 87:(accepted).

Lenoir, J. 1984. The surface flora and its role in the ripening of cheese. IDF Bull. 171:3-20.

Maisnier-Patin, S., and J. Richard. 1995. Activity and purification of linenscin $\mathrm{OC} 2$, an antibacterial substance produced by Brevibacterium linens $\mathrm{OC} 2$, an orange cheese coryneform bacteria. Appl. Environ. Microbiol. 61:1847-1852.

Maoz, A., R. Mayr, and S. Scherer. 2003. Temporal stability and biodiversity of two complex antilisterial cheese-ripening microbial consortia. Appl. Environ. Microbiol. 69:4012-4018.

Ogier, J. C., O. Son, A. Gruss, P. Tailliez, and A. Delacroix-Buchet. 2002. Identification of the bacterial microflora in dairy products by temporal temperature gradient gel electrophoresis. Appl. Environ. Microbiol. 68:3691-3701.

Orita, M., Y. Suzuki, T. Sekiya, and K. Hayashi. 1989. Rapid and sensitive detection of point mutations and DNA polymorphism using the polymerase chain reaction. Genomics 5:874-879.

Purko, M., W. O. Nelson, and W. A. Wood. 1951. The associative action between certain yeasts and Bacterium linens. J. Dairy Sci. 34:699-701.

Randazzo, C. L., S. Torriani, A.D.L. Akkermans, W. M. De Vos, and E. E. Vaughan. 2002. Diversity, dynamics, and activity of bacterial communities during production of an artisanal sicilian cheese as evaluated by $16 \mathrm{~S}$ rRNA analysis. Appl. Environ. Microbiol. 68:1882-1892.

Reps, A. 1993. Bacterial smear-ripened cheese. Pages 137-172 in Cheese: Chemistry, Physics and Microbiology. Vol. 2. Major Cheese Groups. 2nd ed. P. F. Fox, ed. Chapman and Hall, London, United Kingdom.

Schabereiter-Gurtner, C., G. Piñar, D. Vybiral, W. Lubitz, and S. Rölleke. 2001. Rutrobacter-related bacteria associated with rosy discolouration of masonry and lime wall paintings. Arch. Microbiol. 176:347-354.

Seiler, H. 1986. Identification of cheese smear coryneform bacteria. J. Dairy Res. 53:439-449.

Stackebrandt, E., and B. M. Goebel. 1994. Taxonomic note: A place for DNA-DNA reassociation and 16S rRNA sequence analysis in the present species definition in bacteriology. Int. J. Syst. Bacteriol. 44:846-849.

Valdés Stauber, N., S. Scherer, and H. Seiler. 1997. Identification of yeasts and coryneform bacteria from the surface microflora of brick cheeses. Int. J. Food Microbiol. 34:115-129.

Voigt, K., E. Cigelnik, and K. O'Donnell. 1999. Phylogeny and PCR identification of clinically important zygomycetes based on nuclear ribosomal DNA sequence data. J. Clin. Microbiol. 37:3957-3964.

Wintzingerode, F., U. B. Göbel, and E. Stackebrandt. 1997. Determination of microbial diversity in environmental samples: Pitfalls of PCR-based rRNA analysis. FEMS Microbiol. Rev. 21:213-229.

Zoentendal, E. G., A. D. Akkermans, and W. M. De Vos. 2000. Temperature gradient gel electrophoresis analysis of $16 \mathrm{~S}$ rRNA from human fecal samples reveals stable and host-specific communities of active bacteria. Appl. Environ. Microbiol. 64:3854-3859.

Zumstein, E., R. Moletta, and J. J. Godon. 2000. Examination of two years of community dynamics in an anaerobic bioreactor using fluorescence polymerase chain reaction (PCR) single-strand conformation polymorphism analysis. Environ. Microbiol. 2:69-78. 